\title{
Comparative morphology of the seminal receptacles of Ocypode quadrata (Fabricius, 1787) (Brachyura, Ocypodoidea)
}

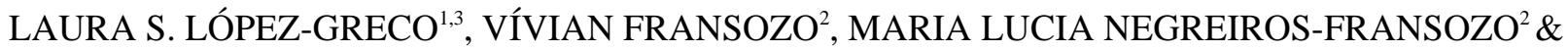 \\ DANIELA CARVALHO DOS SANTOS ${ }^{2}$ \\ ${ }^{1}$ Department of Biodiversity and Experimental Biology, FCEyN, University of Buenos Aires, Ciudad Universitaria, C1428EHA, \\ Buenos Aires, Argentina. E-mail: laura@bg.fcen.uba.ar \\ ${ }^{2}$ Instituto de Biociências, C.P. 510 Universidade Estadual Paulista, 18618-000 Botucatu, São Paulo, Brasil. \\ E-mail:vifransozo@ibb.unesp.br,mlnf@ibb.unesp.br,daniela@ibb.unesp.br \\ ${ }^{3}$ Corresponding author
}

\begin{abstract}
The seminal receptacles of the Eubrachyura are an ecto-mesodermic differentiation of the genital ducts where the spermatophores are stored and fertilization takes place. The position in which the oviduct is connected to the seminal receptacles varies among species and two types, dorsal and ventral, can be distinguished. The dorsal type is frequently observed in the "soft mating system" species, while the ventral one is usually related to the "hard mating system" species. The seminal receptacles (SR) of Ocypode quadrata (Fabricius, 1787) are paired, spherical and opalescent structures with a ventral connection to the oviduct and without any differences between the two members of the pair. The SR present macroscopic features that resemble other semi-terrestrial species of Ocypodoidea and Grapsoidea, but some histological characters resemble more aquatic species such as the Majoidea. The mesodermic portion of the SR is delimited by a cubic-flat secretor epithelium with three layers of muscular cells and surrounded externally by a simple capsule of conjunctive tissue. The transition between the mesodermic and the ectodermic areas is abrupt and characterized by a folded epithelium resembling that described for some Majoidea and the presence of a high cuticular layer. Only free spermatozoa were found, but no differentiated spermatophore packages or spermatophores.
\end{abstract}

Key words: Brachyura, reproductive system, seminal receptacles, sperm competition, sperm storage, Ocypode

\section{Introduction}

Male competition is recognized as an important factor in the evolution of mating systems. As stated by Parker (1970) for insects and posteriorly for other taxa (Parker et al. 1990) sperm competition can be defined as the competition between sperm of at least two males for fertilization of the female oocytes. There is a great potential for sperm competition in species where female store viable sperm for extended periods in specialized organs and mate with more than one male before oocytes are fertilized (Parker 1970; Smith 1984; Diesel 1989; 1991; Jivoff 1997; Wortham-Neal 2002). Pre and post-copulatory mating guarding are usual mechanism for avoiding sperm competition in many taxa, including crustaceans (Parker 1970; revision by Jivoff 1997).

Among decapod crustaceans, Eubrachyuran females have unique paired structures for the storage of spermatophores. These structures are referred to as "seminal receptacles" (Diesel 1988, 1989, 1991; Hinsch 1991; Tavares \& Secretan 1993; González-Gurriarán et al. 1998; Sampedro et al. 1999; or "spemathecae" (Hartnoll 1968, 1969; Paul \& Adams 1984; Bauer 1986; Beninger et al. 1988; Lee \& Yamazaki 1990; Anilkumar et al. 1996; Sainte-Marie et al. 1997,1998, 1999; Gardner et al. 1998; Urbani et al. 1998; Brandis et al. 1999; Rondeau \& Sainte-Marie 2001; Shauna et al. 2004; Rotllant et al. 2007). They are enlargements of 